\title{
SYNTHESIS, CHARACTERIZATION AND INVESTIGATION OF ANTIMICROBIAL ACTIVITY OF SILVER NANOPARTICLES FROM CYDONIA OBLONGA LEAF
}

\author{
BARAN, M. F. \\ Medical Laboratory Techniques, Vocational Higher School of Healthcare Studies, Mardin \\ Artuklu University, 47200 Mardin, Turkey \\ (e-mail:mfiratbaran@gmail.com) \\ (Received $12^{\text {th }}$ Nov 2018; accepted $16^{\text {th }}$ Jan 2019)
}

\begin{abstract}
In this study, leaf extract of Cydonia oblonga were used to synthesize silver nanoparticles. Silver nanoparticles have been successfully synthesized by environmentally friendly and economical methods. Characterization of synthesized AgNPs used UV-visible spectroscopy (UV-Vis.), thermogravimetric and differential thermal analysis (TGA-DTA), X-ray diffraction spectroscopy (XRD), scanning electron microscopy (SEM), electron diffraction X-ray (EDX), Fourier transform infrared spectroscopy (FT- IR). XRD results demonstrated that the crystal structure of AgNPs was cubic and had a size of $27.30 \mathrm{~nm}$. AgNPs were found to be spherical in SEM images. The element composition was also revealed by EDX. Antimicrobial activity of silver nanoparticles; Gram-negative Escherichia coli was tested on gram positive Staphylococcus aureus and Candida albicans yeast. The concentration values of $0.0552,0.1535$ and $0.0383 \mathrm{mg} \mathrm{L}^{-1}$ were determined as MIC (minimum inhibitory concentration), respectively. It was evaluated that the commercial antibiotics used were more effective at low concentrations compared to colistin, vancomycin and fluconazole.
\end{abstract}

Keywords: XRD, SEM, TGA-DTA, silver nanoparticles, Cydonia oblonga

\section{Introduction}

Particles with a size of 1-100 $\mathrm{nm}$ are called nanoparticles. These particles can be obtained by biological, physical and chemical means. They are used in different areas such as energy, pharmacology, biomedical, cosmetics, textiles, food and agriculture etc. (Chaudhry et al., 2018). Compared to physical and chemical methods, the advantages of biological methods such as ease of application and control, eco- friendliness and lack of toxic chemicals make this method important (Pantidos and Horsfall, 2014). Due to the fact that it is cheap and easy to obtain, the use of vegetable resources for synthesis is becoming increasingly common. In the synthesis of silver nanoparticles, phytochemicals in plant leaf extracts form AgNPs by reducing the $\mathrm{Ag}^{+}$ions in the media to the $\mathrm{Ag}^{\mathrm{O}}$ form, and these phytochemicals also provide stability (Prakash et al., 2013). Silver nanoparticles (AgNPs) were synthesized using plant extracts and these particles showed good antimicrobial activity (Ahmed et al., 2018).

In this study, AgNPs were obtained in a very short time with stable, energy-free and room conditions with Cydonia oblonga leaf extract and without any additional chemicals/and or physical steps. The resulting nanoparticles showed a strong antimicrobial effect. In this study a simple and rapid green synthesis of AgNPs is presented.

AuNPs using leaves extract of $\mathrm{R}$. rugosa have been reported. Silver and gold nanoparticles can be prepared with lower amounts of leaf extract and without any additional chemicals/and or physical steps. The effect of leaf extract quantity and concentration of metal solution were also evaluated to optimize the synthesis route producing the metal nanoparticles. 


\section{Materials and methods}

Silver nitrate $\left(\mathrm{AgNO}_{3}\right)$ 99.98\% was obtained from Sigma-Aldrich. Vancomycin, fluconazole and colistin were commercially purchased for antimicrobial applications.

\section{Preparing Cydonia oblonga leaf extract}

The leaf extract of Cydonia oblonga was washed with distilled water and dried at room temperature. $25 \mathrm{~g}$ was taken and the size reduced. It was mixed with $500 \mathrm{ml}$ distilled water and boiled at $85^{\circ} \mathrm{C}$. The extract was filtered through Whatmann No.1 filter paper and cooled to room temperature. Stored at $4{ }^{\circ} \mathrm{C}$ for use in the study.

\section{Synthesis of AgNPs}

$1 \mathrm{mM} \mathrm{AgNO}_{3}$ aqueous solution was used for silver nanoparticles synthesis. It was left to react at room temperature with $125 \mathrm{ml}$ of plant extract and $500 \mathrm{ml}$ of silver nitrate solution was added to $1000 \mathrm{ml}$ of flask and allowed to react under room conditions. AgNPs formation was monitored primarily with a macroscopic method depending on the change of colour and was determined according to time with spectrophotometric measurements (Pugazhendhi et al., 2018). Composed dark colored solution was obtained with centrifuge $(7500 \mathrm{rpm}, 10 \mathrm{~min})$. The top, liquid portion was removed, while the remaining solid segment was washed with distilled water. The resulting AgNPs were left to dry at $65{ }^{\circ} \mathrm{C}$ and stored in the dark until use in the characterization process.

\section{Characterisation techniques}

Synthesised silver nanoparticles (AgNP) UV-Vis. Specrtrums were obtained on a spectrophotometer (UV-1601 220 V SHIMADZU). Scanning electron microscope (EVO 40 LEQ) was used to measure AgNPs dimension and morphology of AgNPs crystal construction was analysed with X-ray diffractometer (RadB-DMAX II) between $3^{\circ} \leq 2 \theta \geq 80^{\circ}$ spaces. SEM- energy dispersive X-ray (EDX) spectroscopy was used to demonstrate AgNPs existence and morphology. FTIR (Perkin Elmer ATR-FTIR) analysis was used to determine those functional groups that has a role in the reduction in the plant extract in the range of $4000-400 \mathrm{~cm}^{-1}$. Thermogravimetric analysis (TGA SHIMADZU DTG-60H) reported the degradation temperatures of AgNPs under the atmosphere of nitrogen gas at $25{ }^{\circ} \mathrm{C} \mathrm{min}-1$ and the atmosphere of nitrogen gas at constant heating rate.

\section{Antimicrobial activity of AgNPs}

The effects of the obtained particles on gram negative Escherichia coli ATCC 25922, gram positive Staphylococcus aureus ATCC 29213 bacteria and Candida albicans yeast were investigated. Minimum Inhibitory Concentration (MIC) was determined by microdilution method. In practice, the muller Hilton medium was added to the microplate wells and incubated overnight at $37^{\circ} \mathrm{C}$ by addition of an appropriate amount of the microorganism mixture and the AgNP solution adjusted to 0.5 in turbidity according to the Mc Farland standard (El-Batal et al., 2018; Vishwasrao et al., 2018; Dhand et al., 2016). The next day the MIC was determined by the well in which the reproduction ended. In addition, vancomycin, colistin and fluconazole commercial 
antibiotics and $1 \mathrm{mM} \mathrm{AgNO}_{3}$ solution were used for S. aureus, E. coli and C. albicans to compare the effects of AgNPs.

\section{Result and discussion}

\section{XRD analysis with $X$-ray diffraction}

The evaluation of the analysis of AgNPs XRD phase and crystal structure was shown in Figure 1, which was synthesised with green method. Crystal structures of silver nanoparticles' reflections (111), (200), (220) and (311) were calculated with the values $2 \theta\left(37.38^{\circ}, 44.78^{\circ}, 64.81^{\circ}\right.$ and $\left.77.50^{\circ}\right)$ on XRD analysis (Fig. 1). It was determined that AgNPs were of elemental $\left(\mathrm{Ag}^{\circ}\right)$ and cubic crystalline structure. The crystalline particle size of the AgNPs was calculated according to the Debye-Scherrer equation and found to be approximately $27.30 \mathrm{~nm}$.

The Debye-Scherrer equation is (Narayanan and Sakthivel, 2011; Banala et al., 2015; Rolim et al., 2019):

$$
D=K \lambda /(\beta \cos \theta)
$$

Here, $\mathrm{D}$ is the crystal size of AgNPs (nm), $\mathrm{k}=$ Scherrer's constant, $(0.90), \lambda=\mathrm{X}$-ray wavelength $\left(1.5406^{\circ} \mathrm{A}\right), \beta=\mathrm{FWHM}$ (full width at half maximum) of the peak located at $2 \theta=37.38^{\circ}, \theta=$ Bragg's angle of diffraction.

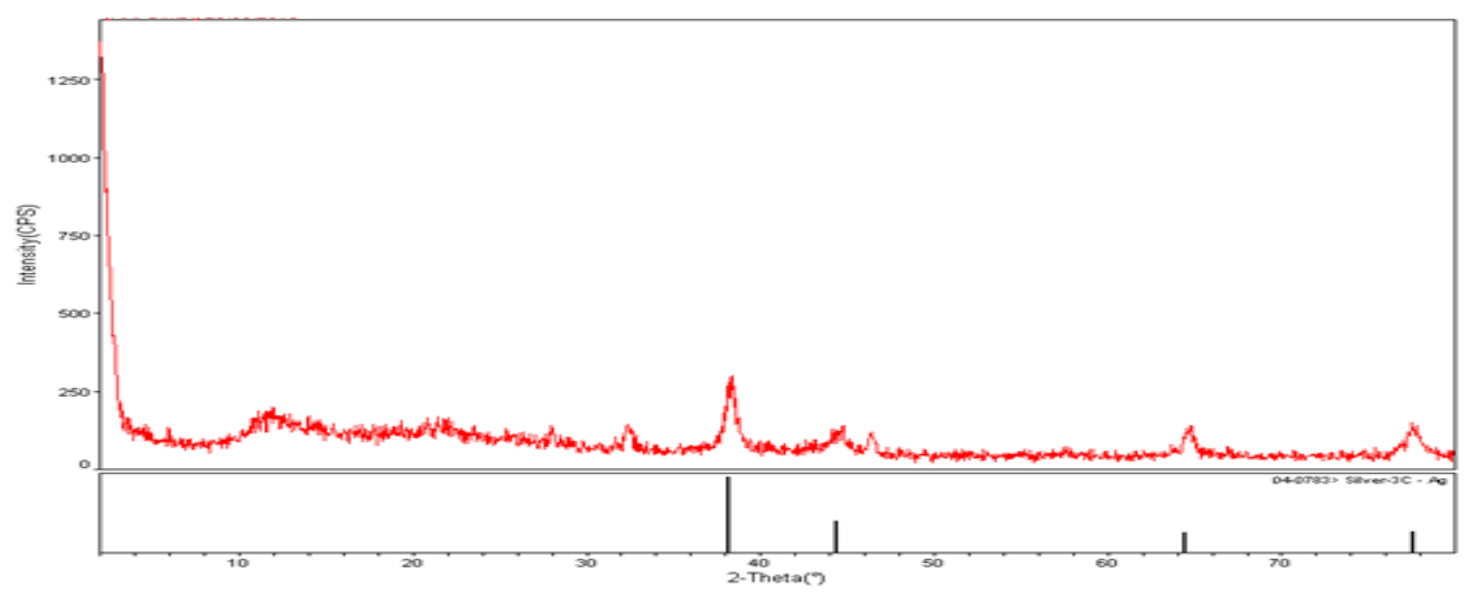

Figure 1. XRD measurements of AgNPs confirming the cubic crystalline structure of AgNPs

\section{Analysis of $U V$-vis spectroscopy}

In UV-vis spectroscopy analysis silver nanoparticles' formation was observed with samples taken at different times at 0, 5, 10, 15, 20, 25, 30 and $45 \mathrm{~min}$. The color change to dark brown, which shows the formation of AgNPs, was observed very quickly. At about a maximum of $441.58 \mathrm{~nm}$ a sharp plazmon resonance indicated appropriately synthesised AgNPs (Fig. 2) Similarly, some other researchers which were near to our research found different spectrum values at 390-500 nm surface plazmon resonance (AlBahrani et al., 2017; Kalimuthu et al., 2008; Anbu et al., 2018; Khan et al., 2018; Rajakumar et al., 2017). 


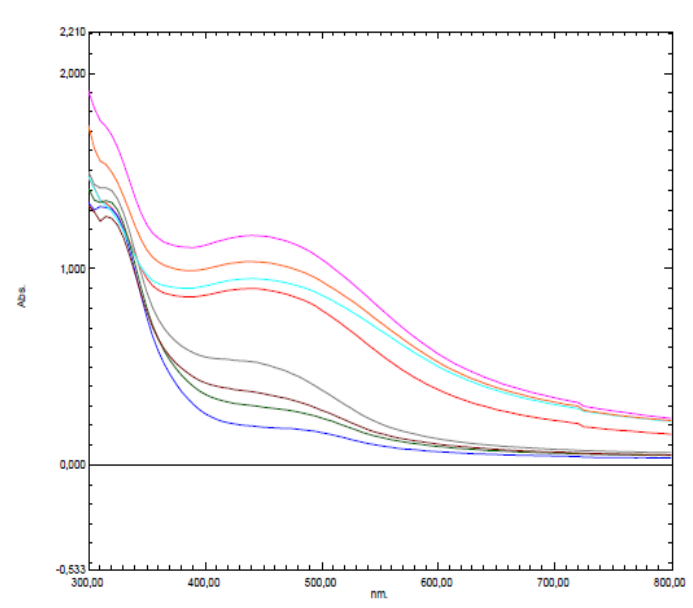

$\mathbf{a}$

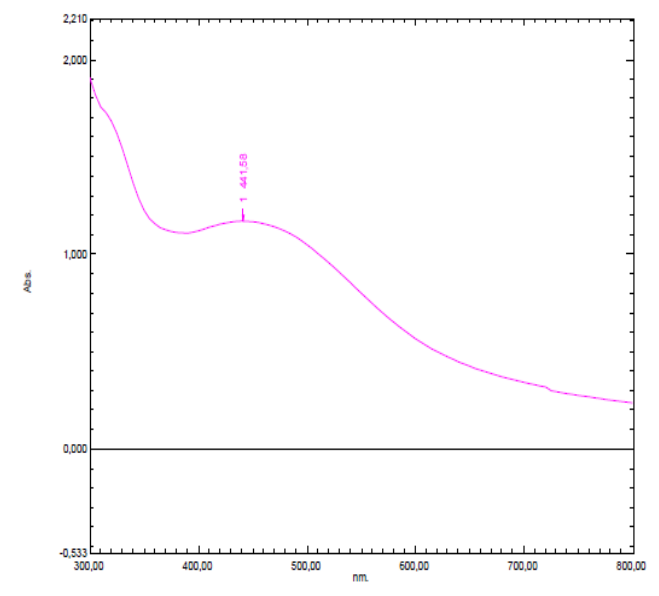

b

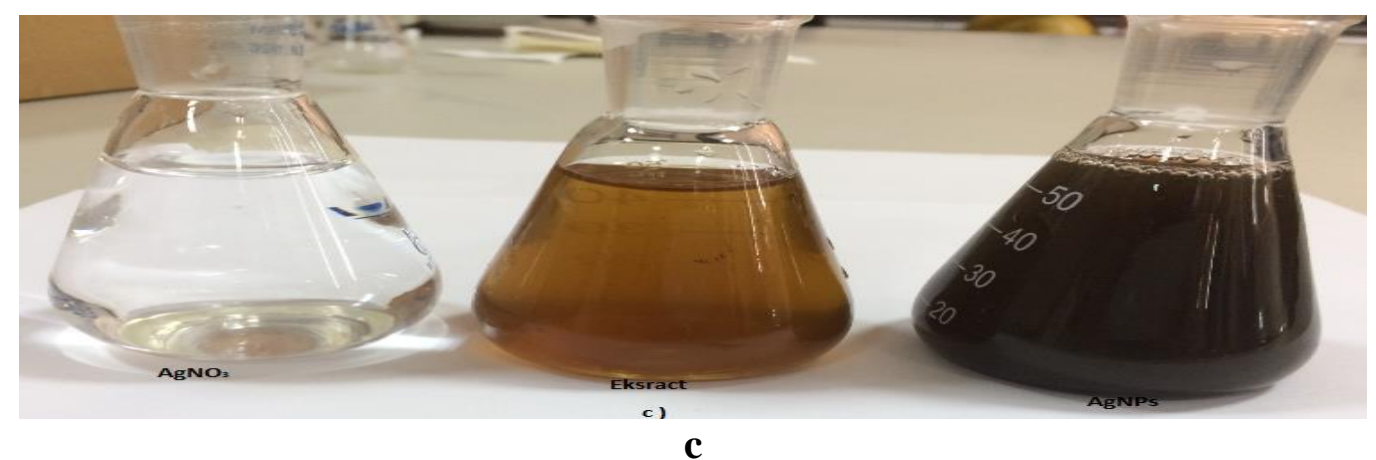

Figure 2. a The UV-Vis spectra of AgNPs synthesized by Cydonia oblonga leaf aqueous extract. $\boldsymbol{b}$ On UV-Vis spectroscopy maximum absorbance value synthesised AgNPs. $\boldsymbol{c} A g N P s$ stepwise thematic representation of the synthesis carried out

\section{Fourier transform infrared spectroscopy (FTIR) spectroscopy analysis}

FT-IR spectrum provided information on which functional groups the reaction occurs in by comparing Cydonia oblonga leaf extract and synthesised AgNPs (Fig. 3). The characteristic peaks appeared at $3291 \mathrm{~cm}^{-1}$ and it represents the $-\mathrm{OH}$ stretching vibrations of free and hydrogen bound hydroxyl groups present in Cydonia oblonga extract. The peak obtained at $2081 \mathrm{~cm}^{-1}$ is due to $-\mathrm{CH}$ stretching vibrations of methylene groups, and furthermore, the sharp peak present at $16365 \mathrm{~cm}^{-1}$ can be assigned to non-hydrated $\mathrm{C}=\mathrm{O}$ groups and it revealed that the asymmetric and symmetric stretching vibrations of carboxyl groups.

FTIR spectrum measurements which were synthesised on different studies showed the existence of intense band on 3314, 2119 and $1636 \mathrm{~cm}^{-1}$ (Pugazhendhi et al., 2018; Baran et al., 2018).

\section{Analysis results of silver nanoparticles SEM and EDAX}

Morphological specifications of AgNPs' which are obtained from leaf extract of Cydonia oblonga were examined by using electron microscope (SEM), shown in Figure 4. The results have shown the presence of silver nanoparticles (AgNPs). Morphological specifications which were obtained from leaf extract of Cydonia oblonga were examined by using electron microscope (SEM), shown in Figure 4. The results have 
shown us clearly the existence of spherical shaped silver nanoparticles (AgNPs') under $100 \mathrm{~nm}$. It was seen on XRD calculation that particles size was about $27.30 \mathrm{~nm}$. Similarly, SEM analysis provided supplementary information about AgNPs size and morphological specifications (De Jesús Ruíz-Baltazar et al., 2017; Prakash et al., 2013; Jha and Shimpi, 2018).

Energy distributed spectrums of acquired AgNPs from EDX analysis have shown that there have been pure silver pieces (Figure 5). The results obtained with AgNPs in other scientific studies support our findings (Veisi et al., 2018; Kumar et al., 2016; Ramkumar et al., 2017).
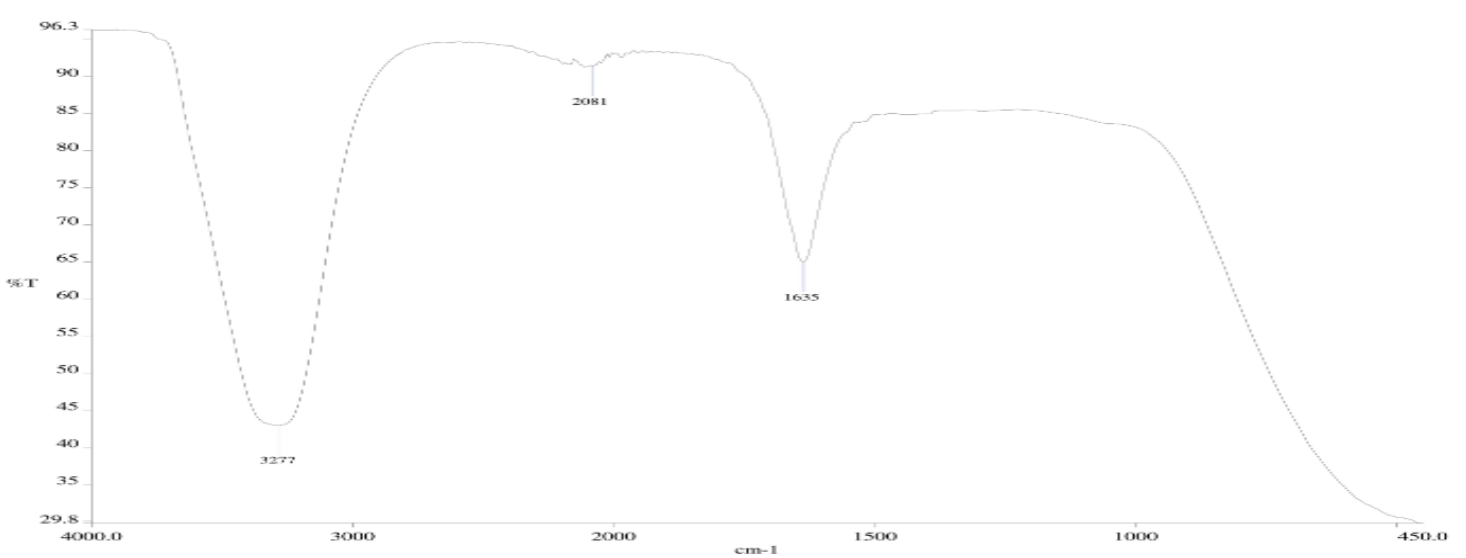

a

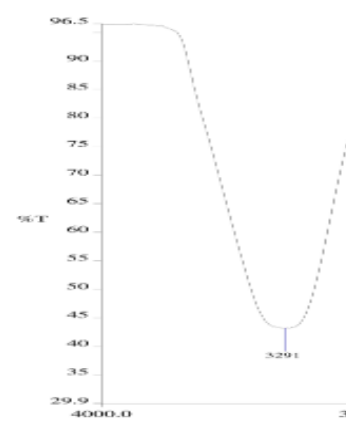

b

Figure 3. a FT-IR spectrum of plant extract spectrum. $\boldsymbol{b}$ FT-IR spectrum of synthesised AgNPs
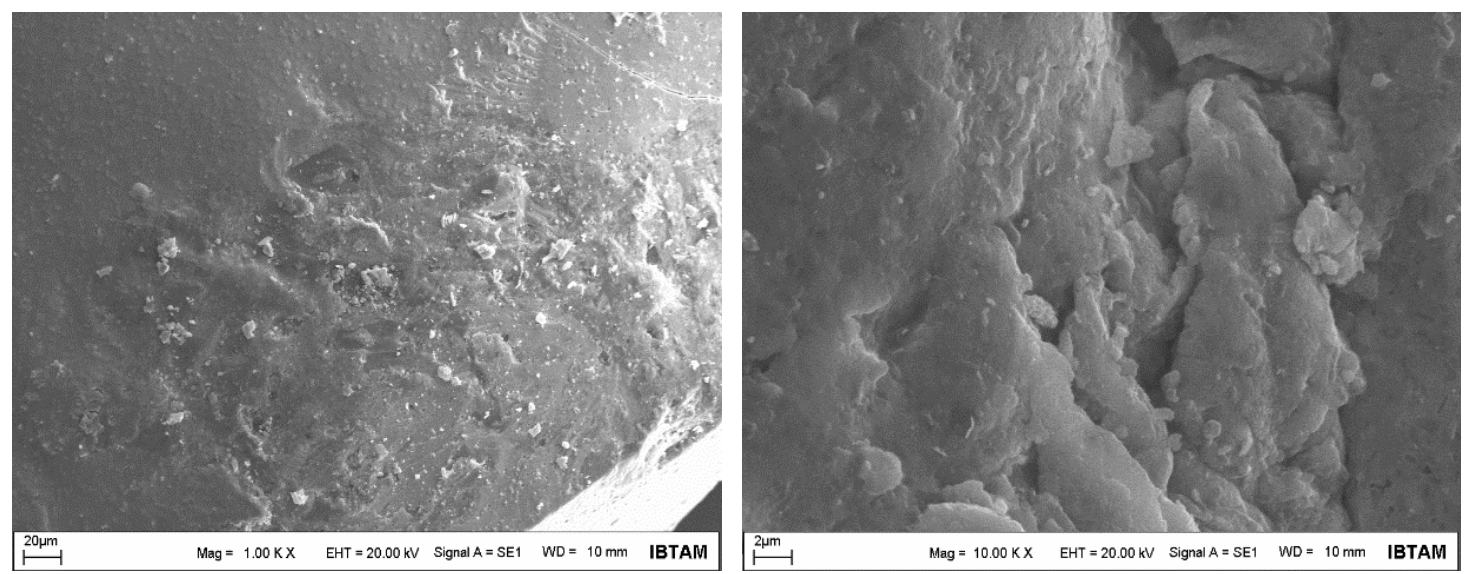


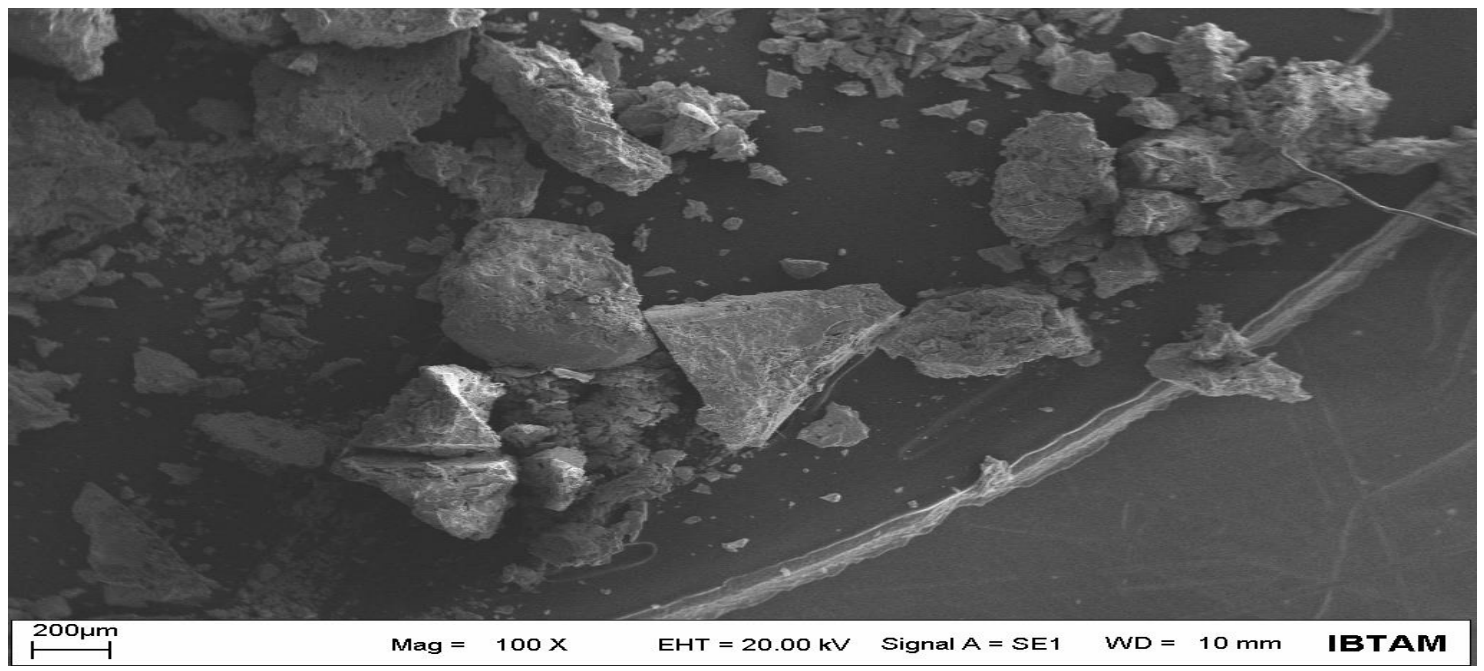

Figure 4. Images of synthesised silver nanoparticles of SEM analyses
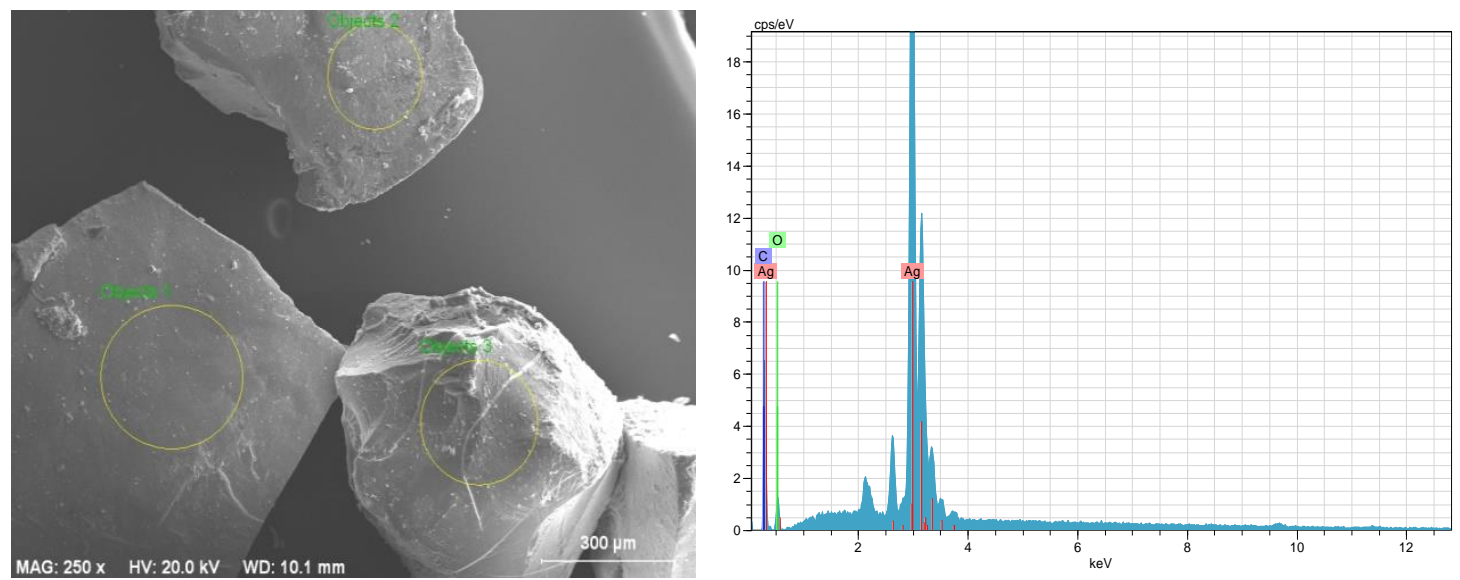

Figure 5. EDX profile of AgNPs showing its elemental composition

\section{TGA-DTA findings}

Nanoparticles which were prepared with green synthesis were analysed with the flow rate of $20 \mathrm{~mL} \mathrm{~min}{ }^{-1}$ in $\mathrm{N}_{2}(\mathrm{~g})$ atmosphere with $10{ }^{\circ} \mathrm{C} \mathrm{min}{ }^{-1}$ heating rate between 31 $900{ }^{\circ} \mathrm{C}$ TGA and DTA data. TGA bent shows specimen mass loss for thermal degradations. DTA bent determines maximum heat of dissociation at every stage of degradation (Baran et al., 2018).

It has been seen in Figure 6 that at $31-257^{\circ} \mathrm{C}$ mass loss is derived from moisture, at $257-333{ }^{\circ} \mathrm{C}$ there is a mass loss which is derived from cellulosic materials, at 333$900{ }^{\circ} \mathrm{C}$ the mass loss is derived from plant extract phytochemicals. TGA data were reported on the study about AgNPs synthesised mass loss. Similar studies support the results in this aspect (Baran et al., 2018).

\section{Antimicrobial activity of synthesised AgNPs}

Microorganisms are more and more resistant to the antibiotics used, which causes the struggle with them to fail. Therefore, the search for antimicrobial agent is more 
interested in combating infection. Antimicrobial activity studies with AgNPs may be a serious alternative to this condition. AgNPs increase the formation of reactive oxygen species (ROS) and disrupt the wall structure. These (ROS) to the affinity of the membrane structure and function changes are produced. They have an antimicrobial effect because they form a repressive process (Wang et al., 2017).
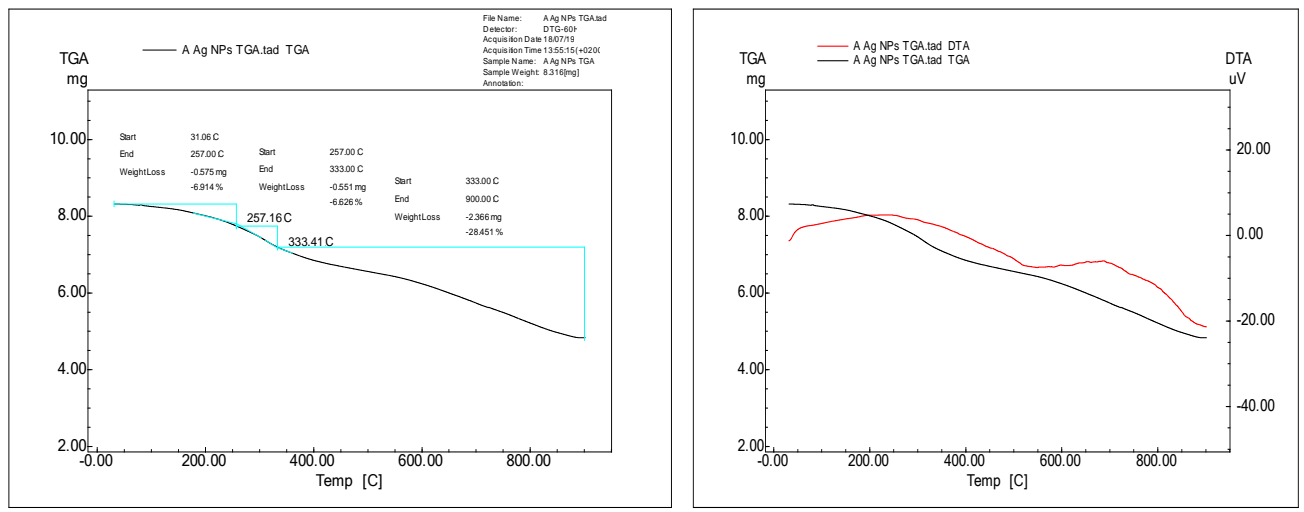

Figure 6. TGA-DTA analysis result of synthesised silver nanoparticles

In our study, the effect of AgNPs' antimicrobial effect is searched which are obtained from leaf extract of Cydonia oblonga by MIC method. Antifungal activities of AgNPs were studied on $C$. Albicans and probable antibacterial effect on gram positive S. aureus ATCC 29213 and gram negative E. coli ATCC 25922. MIC worths were determined of AgNP and $1 \mathrm{mM}$ silver nitrate. In our study, fluconazol, vancomisin and Colistin antibiotics were used. The synthesized silver nanoparticles have been shown to have a strong antimicrobial effect. The MIC of the AgNPs on E. coli ATCC 25922, S. aureus ATCC 29213 and C. albicans was determined as $0.0552,0.1535$ and $0.0383 \mathrm{mg}$ $\mathrm{mL}^{-1}$, respectively. From the acquired results, which have been shown in Table 1, it is clear that AgNPs are more effective than antibiotics and $1 \mathrm{mM}$ silver nitrate solution.

In order to determine the antimicrobial activity of AgNPs, in the other scientific studies, 53, 15 and $40 \mu \mathrm{g} \mathrm{mL}^{-1}$ MIC values were found for E. Coli (Sinsinwar et al., 2018; Rolim et al., 2019; Hemmati et al., 2019). Values of 100 and $11.60 \mu \mathrm{g} \mathrm{mL}^{-1}$ were calculated for E. coli (Ananda et al., 2019; Shao et al., 2018).

Table 1. MIC values of synthesized silver nanoparticles (AgNPs) $\left(m g m L^{-1}\right)$, silver nitrate and S. aureus, C. Albicans, vacomycin, fluconazole, colistin antibiotics for E. coli, respectively

\begin{tabular}{c|c|c|c}
\hline Organism & AgNPs & Silver nitrat & Antibiotic \\
\hline S. aureus ATCC 29213 & 0.1535 & 0.500 & 0.50 \\
C. albicans & 0.0385 & 0.500 & 0.50 \\
E. coli ATCC25922 & 0.0552 & 1.000 & 0.125 \\
\hline
\end{tabular}

\section{Conclusions}

As a result, silver nanoparticles were characterized by UV-visible spectra, TGADTA, FTIR, SEM-EDX and XRD measurements. The nanoparticles were obtained by 
eco-friendly synthesis method with the use of Cydonia oblonga leaf aqueous extract, which does not involve simple, easy and toxic chemicals. In the case of waste, the use of the leaves as a vegetable source for synthesis provides a great advantage both for the recycling of the waste and for the cheap and easy production of the raw material for synthesis. AgNPs obtained by environmentally friendly methods can act as a powerful antimicrobial agent and their contribution to human health in medical industry can be a serious factor. The utilization of the leaf in waste form in this way and the synthesis will be quite interesting considering the transfer of the recycling to the industry. These nanoparticles can also be used for dye removal and bioremediation of waste water.

Acknowledgements. I would like to thank Mardin Artuklu University Scientific Research Project Unit for the support given to MAÜ.BAP.18.SHMYO.040.

\section{REFERENCES}

[1] Ahmed, B., Hashmi, A., Khan, M. S., Musarrat, J. (2018): ROS mediated destruction of cell membrane, growth and biofilms of human bacterial pathogens by stable metallic AgNPs functionalized from bell pepper extract and quercetin. - Advanced Powder Technology 29(7): 1601-16.

[2] Al-Bahrani, R., Raman, J., Lakshmanan, H., Hassan, A. A., Sabaratnam, V. (2017): Green synthesis of silver nanoparticles using tree oyster mushroom Pleurotus ostreatus and its inhibitory activity against pathogenic bacteria. - Materials Letters 186: 21-5.

[3] Ananda, A. P., Manukumar, H. M., Krishnamurthy, N. B., Nagendra, B. S., Savitha, K. R. (2018): Assessment of antibacterial efficacy of a biocompatible nanoparticle PC@ AgNPs against Staphylococcus aureus. - Microbial Pathogenesis 126: 27-39.

[4] Anbu, P., Gopinath, S. C. B., Yun, H. S., Lee, C.-G. (2018): Temperature-dependent green biosynthesis and characterization of silver nanoparticles using balloon flower plants and their antibacterial potential. - Journal of Molecular Structure. DOI: 10.1016/j.molstruc.2018.09.075.

[5] Banala, R. R., Nagati, V. B., Karnati, P. R. (2015): Green synthesis and characterization of Carica papaya leaf extract coated silver nanoparticles through X-ray diffraction, electron microscopy and evaluation of bactericidal properties. - Saudi Journal of Biological Sciences 22(5): 637-44.

[6] Baran, M. F., Duz, M. Z., Uzan, S., Dolak, İ., Celik, K. S., Kilinc, E. (2018): Removal of $\mathrm{Hg}$ (II) from aqueous solution by bacillus subtilis ATC0 (B1). - Journal of Bioprocessing and Biotechniques 8(4): 1-7.

[7] Chaudhry, N., Dwivedi, S., Chaudhry, V., Singh, A., Saquib, Q., Azam, A., Musarrat, J. (2018): Bio-inspired nanomaterials in agriculture and food: current status, foreseen applications and challenges. - Microbial Pathogenesis 123: 196-200.

[8] De Jesús Ruíz-Baltazar, Á., Reyes-López, S. Y., Larrañaga, D., Estévez, M., Pérez, R. (2017): Green synthesis of silver nanoparticles using a Melissa officinalis leaf extract with antibacterial properties. - Results in Physics 7: 2639-2643.

[9] Dhand, V., Soumya, L., Bharadwaj, S., Chakra, S., Bhatt, D., Sreedhar, B. (2016): Green synthesis of silver nanoparticles using Coffea arabica seed extract and its antibacterial activity. - Materials Science and Engineering C 58: 36-43.

[10] El-Batal, A. I., Al-Hazmi, N. E., Mosallam, F. M., El-Sayyad, G. S. (2018): Biogenic synthesis of copper nanoparticles by natural polysaccharides and Pleurotus ostreatus fermented fenugreek using gamma rays with antioxidant and antimicrobial potential towards some wound pathogens. - Microbial Pathogenesis 118: 159-69. 
[11] Hemmati, S., Rashtiani, A., Zangeneh, M. M., Mohammadi, P., Zangeneh, A., Veisi, H. (2018): Green synthesis and characterization of silver nanoparticles using Fritillaria flower extract and their antibacterial activity against some human pathogens. Polyhedron 158: 8-14.

[12] Jha, M., Shimpi, N. G. (2018): Spherical nanosilver: bio-inspired green synthesis, characterizations, and catalytic applications. - Nano-Structures and Nano-Objects 16: 234-49.

[13] Kalimuthu, K., Suresh Babu, R., Venkataraman, D., Bilal, M., Gurunathan, S. (2008): Biosynthesis of silver nanocrystals by Bacillus licheniformis. - Colloids and Surfaces B: Biointerfaces 65(1): 150-3.

[14] Khan, A. U., Yuan, Q., Khan, Z. U. H., Ahmad, A., Khan, F. U., Tahir, K., Shakeel, M., Ullah, S. (2018): An eco-benign synthesis of AgNPs using aqueous extract of Longan fruit peel: antiproliferative response against human breast cancer cell line MCF-7, antioxidant and photocatalytic deprivation of methylene blue. - Journal of Photochemistry and Photobiology B: Biology 183: 367-373.

[15] Kumar, L. D., Sankar, S. S., Venkatesh, P., Kalarani, H. D. (2016): Green Synthesis of Silver Nanoparticles using aerial parts extract of Echinochloa colona and their characterization. - European Journal of Pharmaceutical and Medical Research 3(4): 325328.

[16] Narayanan, K. B., Sakthivel, N. (2011): Extracellular synthesis of silver nanoparticles using the leaf extract of Coleus amboinicus Lour. - Materials Research Bulletin 46(10): 1708-13.

[17] Pantidos, N., Horsfall, L. E. (2014): Biological Synthesis of Metallic Nanoparticles by Bacteria, Fungi and Plants. - Journal of Nanomedicine and Nanotechnology 5(5): 10.

[18] Prakash, P., Gnanaprakasam, P., Emmanuel, R., Arokiyaraj, S., Saravanan, M. (2013): Green synthesis of silver nanoparticles from leaf extract of Mimusops elengi, Linn. for enhanced antibacterial activity against multi drug resistant clinical isolates. - Colloids and Surfaces B: Biointerfaces 108: 255-9.

[19] Pugazhendhi, S., Palanisamy, P. K., Jayavel, R. (2018): Synthesis of highly stable silver nanoparticles through a novel green method using Mirabillis jalapa for antibacterial, nonlinear optical applications. - Optical Materials 79: 457-63.

[20] Rajakumar, G., Gomathi, T., Thiruvengadam, M., Devi Rajeswari, V., Kalpana, V. N., Chung, I. M. (2017): Evaluation of anti-cholinesterase, antibacterial and cytotoxic activities of green synthesized silver nanoparticles using from Millettia pinnata flower extract. - Microbial Pathogenesis 103: 123-8.

[21] Ramkumar, V. S., Pugazhendhi, A., Gopalakrishnan, K., Sivagurunathan, P., Saratale, G. D., Dung, T. N. B., Kannapiran, E. (2017): Biofabrication and characterization of silver nanoparticles using aqueous extract of seaweed Enteromorpha compressa and its biomedical properties. - Biotechnology Reports 14: 1-7.

[22] Rolim, W. R., Pelegrino, M. T., de Araújo Lima, B., Ferraz, L. S., Costa, F. N., Bernardes, J. S., Rodigues, T., Brocchi, M., Seabra, A. B. (2018): Green tea extract mediated biogenic synthesis of silver nanoparticles: characterization, cytotoxicity evaluation and antibacterial activity. - Applied Surface Science 463: 66-74.

[23] Shao, Y., Wu, C., Wu, T., Yuan, C., Chen, S., Ding, T., Ye, X., Hu, Y. (2018): Green synthesis of sodium alginate-silver nanoparticles and their antibacterial activity. International Journal of Biological Macromolecules 111: 1281-1292.

[24] Sinsinwar, S., Sarkar, M. K., Suriya, K. R., Nithyanand, P., Vadivel, V. (2018): Use of agricultural waste (coconut shell) for the synthesis of silver nanoparticles and evaluation of their antibacterial activity against selected human pathogens. - Microbial Pathogenesis 124: 30-7.

[25] Veisi, H., Azizi, S., Mohammadi, P. (2018): Green synthesis of the silver nanoparticles mediated by Thymbra spicata extract and its application as a heterogeneous and 
recyclable nanocatalyst for catalytic reduction of a variety of dyes in water. - Journal of Cleaner Production 170: 1536-1543.

[26] Vishwasrao, C., Momin, B., Ananthanarayan, L. (2018): Green synthesis of silver nanoparticles using sapota fruit waste and evaluation of their antimicrobial activity. Waste and Biomass Valorization 1-11. https://doi.org/10.1007/s12649-018-0230-0.

[27] Wang, M., Zhang, W., Zheng, X., Zhu, P. (2017): Antibacterial and catalytic activities of biosynthesized silver nanoparticles prepared by using an aqueous extract of green coffee bean as a reducing agent. - RSC Adv. 7(20): 12144-9. 